\title{
OS EFEITOS DO FUNDEF NAS POLÍTICAS EDUCACIONAIS DOS MUNICÍPIOS MINEIROS*
}

\author{
Bruno Lazzarotti Diniz Costa** \\ Vanda Catarina Duarte ${ }^{* * *}$ \\ UNESP
}

\begin{abstract}
RESUMO: Este artigo tem por objetivo discutir os efeitos do FUNDEF sobre as políticas educacionais dos municípios de Minas Gerais. As análises estão balizadas em entrevistas realizadas com secretários municipais de educação de uma amostra de 22 municípios, entre novembro e dezembro de 2002. A análise leva em conta um conjunto de argumentos e hipóteses levantado pela literatura, o que inclui a tendência à busca de ganhos de escala e concentração de alunos e estabelecimentos; a possível melhora de remuneração e qualificação do corpo docente; o desenvolvimento de iniciativas de capacitação dos professores; a redução do uso dos recursos vinculados à educação para outros fins; o possível subinvestimento em educação infantil, ensino médio e educação de jovens e adultos, devido à sua exclusão do FUNDEF; e a possível insuficiência do valor de referência do Fundo.
\end{abstract}

PALAVRAS-CHAVE: FUNDEF; Política Educacional; Municipalização

\footnotetext{
* A base empírica do trabalho é a pesquisa O FUNDEF e a municipalização em Minas Gerais: relações intergovernamentais, equidade e controle público, financiada pela Fundação Ford, 2002/2004.

** Doutor em Ciência Política pela Universidade Federal de Minas Gerais. Superintendente de Pós-Graduação e Pesquisa na Escola de Governo da Fundação João Pinheiro. Pesquisador e professor do Mestrado em Administração Pública da Escola de Governo da Fundação João Pinheiro. E-mail: bruno.diniz@fjp.mg.gov.br

*** Mestre em Administração Pública pela Escola de Governo da Fundação João Pinheiro: área de concentração em Gestão de Políticas Sociais. Pesquisadora e Coordenadora de cursos de pós-graduação lato-sensu na área da administração pública na Fundação João Pinheiro. E-mail: vanda.catarina@fjp.mg.gov.br
} 


\section{THE EFFECT OF FUNDEF ON EDUCATIONAL POLICIES OF MINAS GERAIS STATE}

ABSTRACT: This article aims to discuss the effects of FUNDEF on educational policies in Minas Gerais state municipalities. The analyses were based on interviews of local educational secretaries of 22 municipalities of Minas Gerais State carried out between November and December 2002. The analysis considers several points and hypotheses raised in literature, including a trend for the search of gains in scale and the increase of the number of students and schools, a possible improvement in teachers' wages and skills; teacher qualification efforts; reduction in the use the education budget to other ends, the possible underinvestment in preschool, secondary education, and young adult education due to their exclusion from FUNDEF, and the possible insufficiency of the FUNDEF reference value.

KEYWORDS: FUNDEF; educational policy; municipalization

\section{O CENÁRIO EDUCACIONAL}

A política educacional distingue-se da maioria das políticas sociais brasileiras sob a ótica das relações intergovernamentais. A educação pública, principalmente no que se refere ao ensino fundamental, expandiu-se, desde o início, a partir das unidades subnacionais, com a União desempenhando papel complementar, ainda que pouco sistemático e com baixos níveis de eficácia e eficiência, comprometidos, entre outros motivos, pelos problemas de deseconomia de escala. No entanto, a notável expansão do ensino fundamental a partir da década de 1970 padece de qualquer política ou mecanismo de integração entre estados e municípios. Sem uma definição mais clara de competências e de mecanismos intergovernamentais de incentivo à cooperação, o desenvolvimento concorrente e paralelo das redes de ensino fundamental gerou resultados ambivalentes. Por um lado, em termos de disponibilidade de vagas, houve grande avanço na direção da universalização do acesso à educação. Entretanto, o perfil da rede pública de ensino fundamental resultante mostrou-se heterogêneo e desigual. Há grande diversidade entre as regiões quanto à participação relativa das redes estaduais e municipais na oferta de vagas nas diversas etapas do ensino fundamental, além de diferenças também na localização dessas redes, possibilitando o atendimento prioritário da clientela residente nas áreas urbanas ou rurais pelas redes estaduais e municipais.

Cada rede se organizou e expandiu segundo suas próprias lógicas ou prioridades educacionais e/ou políticas. A resultante, além da he- 
terogeneidade mencionada, foi a existência de lacunas e sobreposições na distribuição da oferta de serviços educacionais. Ademais, a rede pública de ensino fundamental enfrenta desigualdades importantes na qualidade dos serviços prestados. Dadas a grande desigualdade do desenvolvimento econômico e social, a capacidade fiscal, administrativa e técnica entre os municípios e estados brasileiros e a ausência de mecanismos para corrigila, a qualidade da educação - e, portanto, as oportunidades educacionais - a que os educandos tinham acesso dependia - ainda dependem -, em larga medida, da rede à qual pertence a escola em que se matriculavam. Essa situação é ainda agravada pelo caráter tendencialmente regressivo da situação: geralmente, é nos municípios e regiões mais frágeis fiscal e administrativamente que se encontram os grupos social e politicamente mais vulneráveis, os quais, recebendo educação de pior qualidade, vêem comprometidas suas possibilidades de rompimento do ciclo de reprodução da desigualdade. Some-se a isso a regressividade das transferências educacionais negociadas da União durante o período, fortemente condicionadas pela capacidade instalada de estados e municípios, favorecendo a concentração dos investimentos e permeadas por critérios pouco claros e clientelísticos de repasse.

Chega-se, assim, ao fim da década de 1980, com um panorama no ensino fundamental caracterizado por avanços importantes na cobertura e no acesso e uma situação muito preocupante do ponto de vista da qualidade e da eqüidade na oferta de oportunidades de escolarização, o que se reflete no desempenho do sistema educacional.

O perfil e a capacitação do corpo docente expressam as características citadas e são centrais para a compreensão da qualidade e da desigualdade educacional no Brasil, como lembram Plank (2001), Xavier e Marques (1991) e Souza (1995), seja por sua importância substantiva para a qualidade e o desempenho do sistema educacional, seja porque as desigualdades salariais sempre foram o principal componente das desigualdades regionais e entre as redes no tocante ao investimento em educação.

Quanto ao perfil e à evolução dos recursos humanos no período, resta enfatizar que as peculiaridades - e os problemas - do federalismo educacional brasileiro permitem (e, em certa medida, produzem) uma disparidade muito alta de salários e de qualificação docentes entre as regiões e entre as diversas redes estaduais e municipais. Essas disparidades eram - e são - as principais componentes das desigualdades nos gastos educacionais públicos no ensino fundamental. As diferentes propostas de 
criação de um piso salarial mínimo para a carreira docente ainda não chegaram a se viabilizar, esbarrando nas capacidades fiscais díspares de estados e municípios e na complexidade dos mecanismos redistributivos que seriam necessários para sua implementação.

Em segundo lugar, houve, ao longo do período, ao mesmo tempo em que se expandiam as redes escolares, a deterioração geral consistente dos salários docentes (mais grave nas redes estaduais), acompanhada da perda progressiva de prestígio da profissão, com a conseqüente piora na formação inicial dos docentes. Com a descentralização fiscal promovida pela nova Constituição, alguns entes conseguiram melhora relativa dessa tendência, o que minimizou ou estagnou, mas não eliminou, a deterioração vivida no período.

Minas Gerais é um caso exemplar das mudanças e dilemas da agenda do ensino fundamental brasileiro. O processo recente de descentralização no ensino fundamental público mineiro ocorreu em duas vertentes: a municipalização e o aumento da autonomia das unidades escolares. A nova Lei de Diretrizes e Bases da Educação Nacional, de 1996, confirmou essa tendência, ao definir que o ensino fundamental - que acumula o maior número de estudantes e de escolas - seria atribuição prioritária dos municípios, que, no entanto, continuam dividindo a competência com os estados. Os estados, por sua vez, além de serem responsáveis pelo ensino médio, manteriam a atuação no ensino fundamental, em regime de colaboração com os municípios. O perfil do sistema escolar público em Minas Gerais vem expressando essa diretriz: se a oferta de vagas no ensino fundamental da rede estadual permaneceu estável entre 1996 e 1997, a oferta no ensino médio da rede estadual aumentou em $18 \%$, chegando a cerca de 470.000 , o que ainda não é suficiente. De qualquer maneira, as redes municipais vinham já acumulando aumento de sua participação no total de vagas, que passou de $23 \%$ do total, em 1996, para cerca de 25\%, em 1997.

Entretanto, foi a implantação do Fundo de Desenvolvimento do Ensino Fundamental e Valorização do Magistério (FUNDEF) que intensificou o processo de municipalização, criando uma estrutura de fortes incentivos e custos financeiros aos municípios, proporcionalmente às vagas que assumissem na rede pública de ensino fundamental.

Pretende-se, com este trabalho, discutir os efeitos do FUNDEF nas políticas educacionais dos municípios mineiros, a partir dos depoimentos dos Secretários Municipais de Educação de 22 dos municípios²: Araxá, Arinos, Barbacena, Belo Horizonte, Betim, Cláudio, 
Caraí, Coroací, Coronel Fabriciano, Francisco Badaró, Governador Valadares, Guaraciaba, Itaipé, Itaúna, Itinga, Nova Lima, Piumhi, Riacho dos Machados, Rubelita, São Thomé das Letras, Timóteo e Uberlândia. As entrevistas com os Secretários Municipais de Educação foram realizadas nos meses de novembro e dezembro de 2002. A seleção desses municípios considerou os seguintes critérios: variação do número de escolas durante os anos subseqüentes à implementação do FUNDEF; repasse do FUNDEF ao município; condição de vida dos municípios; e região do estado em que estão localizados. Os municípios de Belo Horizonte e Betim, ambos na região central do estado, foram incluídos na amostra por duas peculiaridades: primeiramente, pela localização; depois, por deterem os maiores saldos de recursos provenientes do FUNDEF, alterando significativamente a participação do Fundo. Os dados das Tabelas 1 e 2 caracterizam os municípios selecionados de acordo com esses critérios?.

Tabela 1: Municípios selecionados que ganharam recursos do FUNDEF

\begin{tabular}{|c|c|c|c|c|c|c|}
\hline Município & Região & População & Saldo (R\$) & $\left|\begin{array}{c}\text { Pobreza } \\
\%\end{array}\right|$ & IDH & $\mid \begin{array}{c}\% \text { cresci- } \\
\text { mento } \\
\text { estabeleci- } \\
\text { mentos } \\
1997 / 2000\end{array}$ \\
\hline A & CENTRAL & 113.947 & $11.972,00$ & 45,48 & 0,72 & 0,00 \\
\hline B & $\begin{array}{c}\text { CENTRO OESTE DE } \\
\text { MINAS }\end{array}$ & 22.520 & $359.511,00$ & 57,58 & 0,62 & $-33,33$ \\
\hline $\mathrm{C}$ & RIO DOCE & 27.432 & $404.417,00$ & 41,01 & 0,70 & $-14,71$ \\
\hline $\mathrm{D}$ & RIO DOCE & 246.897 & $2.764 .669,00$ & 42,52 & 0,74 & $-4,96$ \\
\hline $\mathrm{E}$ & $\begin{array}{c}\text { CENTRO OESTE DE } \\
\text { MINAS }\end{array}$ & 22.056 & $27.688,00$ & 35,58 & 0,73 & $-18,52$ \\
\hline $\mathrm{F}$ & $\begin{array}{c}\text { JEQUITINHONHA/ } \\
\text { MUCURI }\end{array}$ & 8.789 & $8.551,89$ & 84,68 & 0,39 & -30 \\
\hline G & RIO DOCE & 24.514 & 351,41 & 84,03 & 0,44 & $-21,05$ \\
\hline $\mathrm{H}$ & $\begin{array}{c}\text { JEQUITINHONHA/ } \\
\text { MUCURI }\end{array}$ & 10.694 & 697,34 & 87,09 & 0,379 & $-8,33$ \\
\hline I & NORTE DE MINAS & 10.262 & $1.642,02$ & 84,41 & 0,425 & $-13,89$ \\
\hline $\mathrm{J}$ & NORTE DE MINAS & 10.194 & 561,47 & 85,70 & 0,4 & $-34,21$ \\
\hline
\end{tabular}

Fontes: IBGE. Censo Demográfico, 2000; FJP. Atlas de Desenvolvimento Humano, 2000; IDH 2000; Secretaria de Estado da Educação de Minas Gerais; Censo educacional 1997/2000; e portal mec.gov.Br 
Tabela 2: Municípios selecionados que perderam recursos do FUNDEF

\begin{tabular}{|c|c|c|c|c|c|c|}
\hline Município & Região & População & Saldo (R\$) & $\begin{array}{c}\text { Pobreza } \\
\%\end{array}$ & IDH & $\begin{array}{l}\% \text { cresci- } \\
\text { mento } \\
\text { estabeleci- } \\
\text { mentos } \\
1997 / 2000\end{array}$ \\
\hline K & ALTO PARANAÍBA & 78.848 & -987126 & 34,45 & 0,775 & 11,11 \\
\hline $\mathrm{L}$ & $\begin{array}{l}\text { NOROESTE DE } \\
\text { MINAS }\end{array}$ & 17.710 & -4670 & 74,52 & 0,482 & $-57,14$ \\
\hline M & $\begin{array}{c}\text { JEQUITINHONHA/ } \\
\text { MUCURI }\end{array}$ & 10.294 & -16673 & 88,59 & 0,392 & $-12,5$ \\
\hline $\mathrm{N}$ & MATA & 10.263 & -10665 & 83,28 & 0,438 & $-20,8$ \\
\hline $\mathrm{O}$ & $\begin{array}{c}\text { CENTRO OESTE DE } \\
\text { MINAS }\end{array}$ & 76.783 & -748907 & 34 & 0,761 & 5,71 \\
\hline $\mathrm{P}$ & $\begin{array}{c}\text { JEQUITINHONHA/ } \\
\text { MUCURI }\end{array}$ & 13.836 & -118366 & 87,72 & 0,394 & $-18,75$ \\
\hline Q & CENTRAL & 64.295 & -1371248 & 30,68 & 0,775 & 4,35 \\
\hline $\mathrm{R}$ & SUL DE MINAS & 10.232 & -131389 & 75,19 & 0,505 & 6,67 \\
\hline S & RIO DOCE & 129.076 & -1405281 & 34,9 & 0,782 & 3,85 \\
\hline $\mathrm{T}$ & TRIÂNGULO & 251.159 & -5043350 & 19,77 & 0,795 & 7,76 \\
\hline
\end{tabular}

Fontes: IBGE. Censo Demográfico, 2000; FJP. Atlas de Desenvolvimento Humano, 2000; IDH 2000; Secretaria de Estado da Educação de Minas Gerais; Censo educacional 1997/2000; e portal mec.gov.br

\section{O QUE É O FUNDEF}

O FUNDEF, Fundo de Manutenção e Desenvolvimento do Ensino Fundamental e de Valorização do Magistério, é, desde 1998, um instrumento contábil de gestão educacional. Trata-se de um mecanismo redistributivo entre estados e municípios de parte dos recursos vinculados para o ensino fundamental, criado pela Lei n. 9424, de 24 de dezembro de 1996, com vigência de dez anos, quando foi substituído pelo Fundo de Manutenção e Desenvolvimento da Educação Básica e de Valorização dos Profissionais da Educação (FUNDEB). O FUNDEF se apresenta como um mecanismo institucional de indução a determinados comportamentos por parte dos entes federativos e concentra-se em alguns objetivos:

a) proporcionar maior equilíbrio entre redes estaduais e municipais no que tange à participação e ao compromisso com a ampliação do acesso e da manutenção do atendimento ao ensino fundamental, por meio da vinculação da alocação de recursos para estados e municípios ao número de crianças atendidas pelas respectivas redes de ensino fundamental;

b) diminuir a desigualdade entre os entes federados do ponto de vista dos recursos disponíveis para o ensino fundamental. Isso seria pos- 
sível por meio do estabelecimento do piso de gasto por aluno que orienta o processo de redistribuição de recursos que o FUNDEF põe em marcha: ter-se-iam, portanto, por meio do FUNDEF, desigualdade menor e piso mais alto de gastos por aluno;

c) melhorar progressivamente o perfil e a qualificação do corpo docente do ensino fundamental. $\mathrm{O}$ aumento do piso de gastos com o ensino fundamental, por parte dos entes federados, associado à obrigatoriedade de se aplicarem ao menos $60 \%$ dos recursos do FUNDEF em pagamento de salários e qualificação do corpo docente permitiriam, por um lado, progressiva melhora da qualificação dos atuais professores e, por outro, aumento da atratividade da carreira docente, viabilizando o recrutamento de quadros mais qualificados.

Os recursos do FUNDEF são provenientes de 15\% de impostos e de algumas transferências constitucionais para os estados e municípios. A redistribuição financeira ocorre entre cada governo estadual e seus municípios e entre os próprios municípios de um mesmo estado. Assim, os valores devidos a cada estado e seus municípios são calculados levando-se em consideração o montante de recurso que compõe o fundo no âmbito de cada estado e o número total de alunos matriculados no ensino fundamental público atendidos pela rede estadual e pelas redes municipais, tomando-se como base os dados do Censo Escolar do ano anterior. Dessa forma, é calculado, no âmbito de cada estado, o valor aluno/ ano, a partir da proporção entre a receita total do FUNDEF no respectivo estado e o número total de alunos matriculados no Ensino Fundamental público, regular e especial, nas redes estadual e municipal.

O valor das contribuições dos estados e municípios para o FUNDEF é um percentual fixo de receitas. Já a contribuição da União é flexível, devendo completar o necessário para que os recursos totais do Fundo contemplem a aplicação do valor de referência por aluno. $\mathrm{O}$ dispositivo legal que criou o FUNDEF, proposto pelo Governo Federal, é bom ressaltar, é claro quanto ao critério de cálculo desse valor de referência por aluno, no o art. $6^{\circ}$, parágrafo $1^{\circ}$ da Lei 9424/96:

O valor mínimo anual por aluno, ressalvado o disposto no parágrafo $4^{\circ}$, será fixado por ato do Presidente da República e nunca será inferior à razão entre a previsão da receita total para o Fundo e a matrícula total do ensino fundamental no ano anterior, acrescida do total estimado de novas matrículas, observado o disposto no art. $2^{\circ}$, parágrafo $1^{\circ}$, incisos I e II.

De acordo com a lei, os recursos do Fundo devem ser aplicados da seguinte forma: pelo menos $60 \%$ na remuneração dos profissionais do 
magistério em efetivo exercício de suas atividades no ensino fundamental público; os 40\% restantes deverão ser aplicados na manutenção e no desenvolvimento do ensino fundamental público e na valorização de seu magistério. ${ }^{4}$

De forma a garantir que a repartição, a transferência e a aplicação desses recursos sejam exercidas de forma transparente junto aos respectivos governos, tanto no âmbito da União quanto no âmbito dos estados, do Distrito Federal e dos municípios, foram instituídos, por meio da mesma lei, conselhos, em cada esfera de governo, com a finalidade de acompanhar e controlar a utilização dos recursos.

\section{PRINCIPAIS EFEITOS E DIFICULDADES E RELACIONADOS AO FUNDEF}

Os efeitos e dificuldades relacionado ao FUNDEF serão analisados a partir de um conjunto de argumentos,comumente apresentados na literatura por diferentes especialistas da área da educação. A proposta é procurar identificá-la a partir da pesquisa de campo realizada.

Argumento 1: A implementação do FUNDEF criaria uma estrutura de fortes incentivos e custos financeiros aos municípios, proporcionalmente às vagas que assumissem na rede pública de ensino fundamental. Iss geraria a reconfiguração abrangente da oferta de ensino fundamental, incluindo intensificação do processo de municipalização, redução do número total de escolas e aumento do número de alunos por estabelecimento e por turma.

A municipalização, uma tendência manifesta nos últimos anos, decorre da maior autonomia dos municípios desde a Constituição Federal de 1988 e dos problemas fiscais dos estados. Em Minas Gerais, por exemplo, entre 1996 e 1997, as redes municipais aumentaram em 8\% o atendimento ao ensino fundamental, enquanto a rede estadual praticamente permaneceu estável.

No que se refere ao efeito municipalização, apenas quatro dos secretários entrevistados a apontaram como impacto do Fundo. Para os demais, o processo de municipalização não foi decorrente do FUNDEF, mas principalmente da LDB 9394/96, que passou a exigir que os municípios assumissem a educação fundamental. Observa-se, no entanto, que a municipalização foi mais intensa no período 1996/1998 e sofreu redução após 1998, coincidindo com a implementação do Fundo. Em alguns municípios ( $\mathrm{R}, \mathrm{V}$ e $\mathrm{P}$ ), a municipalização foi pequena, cor- 
respondendo a cerca de três escolas por município. Em outros (H e E), esse processo dependeu de intensa negociação junto ao estado, envolvendo divisão de responsabilidades como: o município assumir um ciclo do ensino fundamental e o estado, o outro; ou o estado assumir o salário-base de vários professores até o ano 2000 e o município, a partir daí.

Dois aspectos negativos da municipalização foram ressaltados: a perda de cargos anteriormente efetivos e o aumento das despesas do município. $\mathrm{O}$ argumento era de que o governo federal, ao implementar o processo de municipalização, transferiu uma série de obrigações constitucionais que eram suas para o governo estadual, que, por sua vez, as transferiu para o município. "O problema é que tais obrigações são transferidas sem o repasse de um valor adequado para as prefeituras, que, geralmente, não têm condições de arcar com as novas responsabilidades" "Tal afirmação refere-se ao não-reajuste do valor nacional por aluno que é repassado para o município e que se manteve praticamente o mesmo desde 1997 ( $\mathrm{R} \$ 315,00)$, passando para $\mathrm{R} \$ 365$,00, em 1999, permanecendo neste valor até então. Como será discutido adiante, isso significou o não-recebimento, pelo estado, de complementação da União.

Outra queixa constante refere-se à falta de preparo técnico prévio para suavizar os impactos do processo de descentralização educacional e ajudar o planejamento da municipalização e a gerência do recurso disponibilizado pelo FUNDEF. Tal queixa se mostra perfeitamente pertinente, uma vez que aumentar as fontes de recursos dos municípios ou transferir recursos para que esses possam assumir funções de gestão de políticas educacionais não é suficiente, já que a capacidade de gestão está relacionada com a capacidade técnica instalada no município e com seu porte socioeconômico, sendo que a natureza política e as capacidades econômica e administrativa nos municípios mineiros são bastante diferenciadas. De acordo com Costa e Veiga (2002, p. 71), dadas as diferentes capacidades dos municípios, um processo pouco cuidadoso pode resultar em descontinuidade ou perda da qualidade no atendimento, principalmente no caso dos municípios mais frágeis economicamente, nos quais há maior concentração de pobreza e baixa concentração de recursos humanos qualificados.

Parece claro que um processo de municipalização, para ser efetivo, teria de incorporar essas diferenças no planejamento, de forma a verificar como cada município poderia assumir maiores responsabilidades na oferta de um ensino de qualidade. A ausência desse planejamento pode implicar efeitos perversos, como a baixa qualidade do ensino oferecido e 
mesmo o aumento de disparidades entre os municípios em lugar da desejável redução. Um exemplo de ensino de baixa qualidade seria as classes multisseriadas integradas por crianças com capacidades e necessidades diferenciadas de aprendizagem sob a responsabilidade de profissionais cuja qualificação se situa muito aquém do desafio a que teriam de responder, como se verificou em alguns municípios $(\mathrm{V}, \mathrm{P}, \mathrm{M}, \mathrm{U}$, $\mathrm{B}, \mathrm{L}, \mathrm{K}, \mathrm{O}$ e $\mathrm{R})^{6}$ - todos municípios menores, que se localizam em áreas de pobreza do estado e de baixo IDH (Índice de Desenvolvimento Humano).

Desse ponto de vista, é possível argumentar que a municipalização não diminui, mas aumenta a responsabilidade do governo estadual, que passa a ter atribuições crescentes na coordenação da política de descentralização. Isso implicaria exercer, de forma rigorosa e consistente, as funções de coordenação, supervisão e assessoria técnica às redes estaduais e municipais de ensino. $\mathrm{O}$ apoio financeiro deveria estar balizado por diagnósticos sobre as necessidades técnicas das redes em cada município, dos desafios pedagógicos que enfrentam e do envolvimento do município na atenção às demandas, o que não se verificou em nenhum dos municípios visitados.

O que se observa nos depoimentos é que os Secretários não relacionam diretamente a municipalização ao FUNDEF. Supõe-se que esse resultado tem a ver com o esgotamento de seus efeitos, uma vez que houve, a partir de 2001, significativa redução desse processo, e com o fato de a maioria dos entrevistados ser de gestão mais recente, que não vivenciou, portanto, os efeitos mais imediatos do Fundo.

O impacto do FUNDEF sobre a reconfiguração da oferta da rede pública de ensino é impressionante, estimulando o processo de municipalização e aumentando, em muitos casos, o compromisso dos municípios com a educação. De acordo com Costa e Veiga (2002, p. 6), em Minas Gerais, em 1996, as redes municipais eram responsáveis por cerca de $25 \%$ e a rede estadual por $75 \%$ das matrículas na rede pública do ensino fundamental. Em 1997, a oferta total de matrículas no ensino fundamental público aumentou cerca de $2 \%$, com as redes municipais ampliando sua participação no total de matrículas para cerca de 26,5\%. Em relação a 1996, as redes municipais aumentaram suas matrículas no ensino fundamental em $8 \%$, enquanto a rede estadual se manteve praticamente estável, com aumento de 0,3\%. Em 1998, no entanto, a situação se alterou bastante devido, provavelmente, à vigência da nova LDB, mas, em particular, ao FUNDEF, com sua forte estrutura de 
incentivos e desincentivos financeiros. Houve crescimento no total de matrículas na rede pública de ensino fundamental de 5\% em relação a 1997. Mas seu perfil mudou radicalmente. As redes municipais se expandiram em impressionantes $64 \%$, enquanto a rede estadual diminuiu em 15\% sua oferta de vagas. Em 1998, a participação relativa das redes municipais no total de matrículas no ensino fundamental saltou para $41 \%$.

Segundo Santos (2003, p. 36), em 2001 observou-se o processo inverso à municipalização, quando alguns municípios estadualizaram matrículas do ensino fundamental de Minas Gerais - foram estadualizadas 12.406 matrículas do ensino fundamental. Esse processo foi decorrente da necessidade do estado de ter de volta suas matrículas devido ao número de servidores excedentes e de os municípios não terem condições de assumir as matrículas, uma vez que as adjunções e/ou disposições de servidores que ocorreram em 1998, com ônus para o estado, passaram a ser ônus dos municípios. Outra explicação está no fato de que o estado investe no ensino médio com sobras de recursos do ensino fundamental. Como este passou a ser responsabilidade dos municípios, tornou-se difícil para o estado manter o ensino médio, cuja demanda apresenta tendência de crescimento.

Os esperados aumentos do número de matrículas e do número de alunos em salas de aula só se verificaram no relato dos Secretários de dois municípios ( $\mathrm{N}$ e $\mathrm{P}$ ) - ambos localizados no norte de Minas. Entretanto, dados da SEE/MG revelam que, no período 1997-2000, o número de matrículas aumentou na rede municipal de ensino em todos municípios visitados a partir de 1998, apresentando redução apenas na rede estadual. Conseqüência esperada do processo municipalização ocorrido no estado a partir dessa data e da melhoria do acesso à educação.

A partir de 2001, há de fato redução do número de matrículas nas duas redes em grande parte dos municípios visitados. Redução essa que pode estar relacionada às mudanças demográficas e de melhorias no fluxo por meio da redução das taxas de evasão e repetência e, também, da eliminação da retenção em muitas escolas de ensino fundamental.

Argumento 2: Com a obrigatoriedade de aplicar pelo menos 60\% dos recursos do FUNDEF para remuneração de professores, haveria melhora significativa na remuneração desses profissionais, o que contribuiria para o aumento da qualificação docente.

A lei que regulamenta o Fundo estabelece a obrigatoriedade da aplicação de, no mínimo, $60 \%$ dos recursos retidos para a remuneração do 
pessoal do magistério, em efetivo exercício de suas atividades no ensino fundamental público $\left(\operatorname{art} .7^{\circ}\right)$.

De acordo com o MEC (1999, p. 16), os professores brasileiros tiveram aumento médio de salário de 12,9\% em 1998, chegando a 29\% em 2000 (PARAGUASSU, 2001, p. 3). O ganho salarial variou de acordo com o grau de formação: 33,3\% para os de ensino fundamental; 17,9\% para os de ensino médio com magistério; e 10,2\% para os de licenciatura plena. Destaca-se que o maior aumento salário deu-se nas redes municipais de ensino, principalmente na região nordeste, onde os salários cresceram, em média, 49,6\%. Não se pode negar o mérito do FUNDEF em promover a transformação dos salários dos professores, como se pode perceber na afirmação de Monlevade e Ferreira (1998, p. 9): “(...) é verdade que houve conseqüências espetaculares, de transformação do valor de salários de $\mathrm{R} \$ 30,00$ para $\mathrm{R} \$ 230,00$, em muitos municípios, principalmente de estados do Nordeste (...)".

O grande impacto do FUNDEF, segundo os entrevistados, foi na remuneração dos professores e na conseqüente regularização do pagamento, que sofria atrasos em muitos municípios, principalmente nos menores. O impacto na folha de pagamento para alguns municípios ( $\mathrm{U}, \mathrm{B}$, $\mathrm{S}, \mathrm{A}$ e $\mathrm{M}$ ) é de tal ordem que eles temem não poder sustentá-la com a possível extinção do Fundo, já que só tem sido possível oferecer bons salários e capacitação devido aos recursos repassados. Essa é também a situação dos municípios que, antes do FUNDEF, pagavam aos professores menos de um salário mínimo $(\mathrm{N}$ e K), um salário mínimo $(\mathrm{M}$, P e O) ou um salário mínimo e meio (Q) - todos municípios situados nas regiões de pobreza do estado.

Alguns dos entrevistados não atribuem ao Fundo a melhoria salarial de seus professores (municípios $G$ e D ). De acordo com o primeiro (G), o município instituiu, em 1995, o estatuto público do magistério, que sustenta um plano de carreira no qual professores, pedagogos e diretores já tinham se beneficiado com aumentos salariais. Apesar de o ganho salarial dos professores desse município preceder FUNDEF, o entrevistado foi enfático ao afirmar que praticamente todo o recurso repassado pelo Fundo é gasto na manutenção desses salários. Quanto ao segundo (município D), o entrevistado afirmou que o Fundo não promoveu no município aumento real de salários, mas possibilitou o pagamento da folha que tinha dificuldade em pagar. Para outros entrevistados ( $\mathrm{T}$ e A), o ganho salarial dos professores foi conseqüência tanto do FUNDEF quanto da luta e da reivindicação da categoria. 
Pode-se observar, a partir das entrevistas, que houve melhora significativa no salário dos professores, principalmente daqueles que atuam em municípios mais carentes $(\mathrm{N}, \mathrm{O}, \mathrm{Q}, \mathrm{U}, \mathrm{M}$ e $\mathrm{K})$, para os quais o recurso torna-se imprescindível para esse fim. Destaca-se que, com exceção do município $Q$, todos esses municípios ganham com o FUNDEF.

Argumento 3: Com recursos do Fundo, os municípios teriam melhores condições para capacitar seus professores.

Um dos principais enfoques do FUNDEF é a valorização do magistério e a conseqüente melhoria da qualidade do ensino fundamental oferecido. De acordo com a lei, essa valorização se daria a partir da melhoria salarial dos professores, da elaboração de um plano de carreira para a categoria e da capacitação, principalmente dos professores leigos. No que se refere à capacitação, a lei explicita que os $60 \%$ destinados ao pagamento de professores poderiam ser utilizados, até cinco anos, a contar da publicação da lei, para capacitação de professores leigos. Não há um percentual previamente definido para esse fim, ele está embutido no percentual destinado ao pagamento dos professores. Monlevade e Ferreira (1998, p. 46) vêem essa proposta como abusiva. Para os autores, os governos, tanto federal quanto estadual, estariam se desresponsabilizando e delegando aos professores a responsabilidade pela formação dos colegas leigos. Para os autores, uma vez que a LDB/96 estabelece 2007 como o ano-limite para que todos os docentes estejam habilitados para a função, o estado é que deveria disponibilizar recursos para esse fim.

Essa limitação de recursos tem feito com que a capacitação de professores nos municípios sofra diferentes desenlaces. Alguns municípios deixam de oferecê-la, outros a oferecem com recursos próprios e há ainda aqueles que buscam convênios/parcerias para esse fim.

Os municípios que não têm investido em capacitação dos professores alegam que os recursos repassados pelo FUNDEF têm sido insuficientes, cobrindo apenas o pagamento dos salários dos professores (municípios G e A). O município L apresenta situação interessante: para poder investir em capacitação, os professores terão de passar a receber salários menores. "O recurso do FUNDEF, 60\% para professores... aparentemente melhorou o salário do professor. Mas não melhorou. Porque desse recurso tem que se tirar a formação dos professores. Então 
você tira a formação e não sobra nada. (...) Mas aí as professoras, piso salarial de $R \$ 240,00$, elas estavam recebendo $R \$ 300,00, R \$ 400,00$, agora só vão receber os $\mathrm{R} \$ 240,00$ ”"

A fala da entrevistada revela certa incompreensão da utilização do Fundo, uma vez que a capacitação deve ser oferecida com os $40 \%$ restantes do recurso, e não com os $60 \%$ previstos para pagamento de salários, salvo para capacitação de professores leigos.

A dificuldade na capacitação de professores está relacionada ao fato de elas, muitas vezes, ocorrerem longe dos municípios (é o caso do projeto Veredas ${ }^{8}$, que envolve deslocamentos), limitando o acesso pelos municípios mais distantes e mais pobres. Nesse caso, se a prefeitura não levar os professores para fazê-los, eles não irão por conta própria em razão do custo e da distância.

Para alguns municípios (N, F, L, U, O, R e V), o investimento em capacitação significa ajuda de custo ou facilitações, como fornecimento de transporte, diárias ou ajuda com pagamento de faculdade e magistério. Para estes, o investimento em capacitação no período 1998/2000 ocorreu basicamente com a formação/habilitação dos docentes do ensino fundamental e com a complementação dessa formação com cursos como PROCAP e PROCAD 9 . Cabe ressaltar que todos os entrevistados ressaltaram a participação de seus professores nesses cursos e no Projeto Veredas $^{10}$. Da mesma forma, todos sinalizaram a preocupação com a formação de nível superior para seus professores.

Foi frisado, também, que alguns municípios não oferecem regularmente programas de capacitação aos professores mais pela dificuldade em se montar cursos de qualidade no município e menos por falta de interesse.

Ainda no que diz respeito à capacitação de professores, muitos municípios promovem sua própria capacitação, seja com recursos próprios, seja com diferentes parcerias. No âmbito das parcerias e/ou convênios, cabe citar os municípios K, H, D e A.

$\mathrm{O}$ município $\mathrm{H}$ tem investido na formação continuada de seus professores com outros recursos que não o FUNDEF e através de convênios com a Secretaria de Estado da Educação e com o instituto de ensino local. O primeiro convênio refere-se ao Projeto Veredas, para o qual o município encaminhou 128 professores. O segundo visa a oferecer a formação de magistério superior para os professores que não têm e ainda não estão cursando curso superior. No município D, a partir de 2000, foi feita uma parceria com uma universidade para a formação em 
normal superior de 110 professores. O secretário do município A afirma que os cursos de capacitação têm sido bancados ou pela prefeitura ou por meio de convênio com o governo federal. A secretária traz profissionais de fora do município para oferecer a capacitação.

Entre os municípios que investem em capacitação com recursos próprios citam-se o T, J e I. O município T, apesar de ganhar com o repasse do FUNDEF, não atribui a ele sua política de capacitação. Segundo o secretário, o município possui um centro de formação de professores desde 1990. Em função disso, 85\% dos professores da rede municipal têm curso superior, o que torna o município confiante em atender a demanda colocada pela LDB para 2007. O município J possui, desde 1992, o Centro de Estudo e Projetos Educacionais, com o objetivo de desenvolver atividades de formação continuada para os profissionais da rede municipal de ensino. O Centro, que é mantido pela prefeitura, desenvolve atividades como cursos, oficinas, grupos de estudos, seminários, conferências, reuniões, mostra de trabalhos e outros. A partir de 1999/2000, o Centro passou a oferecer o normal superior - o único com recursos do FUNDEF. No município I, a capacitação de professores também é realizada com recursos da prefeitura e se destina a todos os níveis de ensino. Atualmente, numa parceria com a Universidade Federal de Ouro Preto (UFOP), a prefeitura está pagando o normal superior para os professores.

Destacam-se, entre os municípios que capacitam com recursos do FUNDEF, os municípios K, B, S, C e E. A capacitação no município $\mathrm{K}$ tem privilegiado, até o momento, a formação em ensino médio para os professores de $1^{\mathrm{a}}$ a $4^{\mathrm{a}}$ séries.

No município B, a capacitação tem sido pensada de acordo com as necessidades dos professores. No município $\mathrm{S}$, foi implantado o Centro de Formação do Educador, que oferece cursos rápidos, palestras, conferências e possibilidades de viagens para aprimoramento científico dos educadores. Além disso, oferece aos profissionais que têm interesse em cursar programas de mestrado e doutorado liberação com ônus total para a prefeitura. Tais programas são possíveis, segundo o secretário, graças aos recursos do FUNDEF. Entre 1998 e 2000, o município E investiu na capacitação de professores, oferecendo cursos para a préescola, para professores do ensino fundamental de $1^{\mathrm{a}}$ a $4^{\mathrm{a}}$ séries e cursos de alfabetização.

Observa-se, pelas entrevistas, certo interesse pela capacitação dos professores, principalmente em nível superior, de forma a atender o 
estabelecido na LDB de 1996. Apesar de o empenho estar mais voltado para o cumprimento dessa exigência, nota-se um esforço importante por parte dos municípios em capacitar seus professores. O esforço da capacitação se faz notar pelas alternativas adotadas: estabelecimento de convênios, oferecimento de facilidades para uma capacitação fora do município e a utilização de recursos extra-FUNDEF para esse fim. Entretanto, pode-se notar, pelas entrevistas, que a capacitação foi mais freqüente em municípios de situação socioeconômica melhor.

Observa-se, também, que em municípios maiores, como T, A J e I, os relatos dos secretários foram no sentido de desresponsabilizar o FUNDEF pelas ações adotadas ali, principalmente as de capacitação. Essa constatação permite afirmar que a necessidade do Fundo pode estar relacionada ao perfil socioeconômico do município.

Argumento 4: O FUNDEF permitiria melhor emprego dos recursos educacionais, evitando a utilização desses para outros fins.

Outro impacto significativo do Fundo diz respeito ao emprego correto dos recursos e ao aumento do investimento de recursos com educação, favorecendo a qualidade do ensino oferecido e a melhoria no atendimento. Municípios que investiam pouco no ensino fundamental, sob pena de perda de recursos, se viram compelidos a repensar suas políticas para o setor. A obrigatoriedade de um recurso para a educação, além de dar mais autonomia ao município, permitindo melhor planejamento sobre a forma de utilização desse recurso, evita que este seja desviado para outras finalidades ou outras rubricas, como cultura, esporte, etc.

Quanto a este ponto, uma inovação importante do FUNDEF foi a criação dos Conselhos de Acompanhamento e Controle Social, formados por membros dos governos e da sociedade civil que têm a atribuição de acompanhar e contribuir para a aplicação adequada dos recursos do Fundo. Os CACS, apesar de enfrentarem ainda muitas limitações, têm dado contribuição importante para o aumento da transparência e da accountability neste campo ${ }^{11}$.

A vinculação de recursos para a educação foi destacada pela maioria dos entrevistados (20). A secretária municipal de educação do município $\mathrm{U}$, por exemplo, ressalta a comodidade de se ter disponibilizado um recurso específico para educação. Para ela, "o município tem condições de capacitar os professores porque tem os $40 \%$ que se gastam em transporte escolar ou em capacitação ou em reformas. Você tem este 
dinheiro de que pode lançar mão e pode usar como precisar, desde que em educação"

Para o secretário do município $\mathrm{D}$, a vinculação dos recursos da área de educação permitiu maior autonomia à Secretaria Municipal de Educação em relação à prefeitura, na condução da política educacional do município, em especial no ensino fundamental.

Observa-se, pelas entrevistas, que a vinculação dos recursos para educação, definindo inclusive os percentuais a serem gastos com determinadas rubricas, foi um ganho para o setor, que não teve seus recursos despendidos para outro fim e para os secretários municipais de educação, que passaram a ter maior autonomia na gestão desses recursos.

Argumento 5: A exclusão da educação infantil, classes de alfabetização e educação de jovens e adultos do rateio do FUNDEF tem gerado dificuldade de gerenciamento da educação pelos secretários municipais e subinvestimento nessas modalidades de ensino.

Sem a entrada de novos recursos na educação e com a indução à atenção ao ensino fundamental, estados e municípios vêem-se em dificuldades para fazer frente às demandas da educação infantil, substantivas e constitucionalmente tão importantes quanto o ensino fundamental. Assim, o FUNDEF, como está estruturado, é insuficiente para contemplar de forma satisfatória a questão central da criação de um regime de colaboração entre os entes federativos, conforme determinado pela LDB. além disso, caso persista o atual arranjo institucional e contábil, o FUNDEF pode transferir para os outros níveis de ensino os problemas relativos à barganha federativa ou, de forma mais simples e perversa, relegálos ao abandono.

Em seu artigo $1^{\circ}$, a lei 9424/96 estabelece que serão consideradas para distribuição dos recursos do Fundo "as matrículas de $1^{\text {a a }} 8^{\text {a }}$ séries do ensino fundamental", excluindo a educação infantil e a educação de jovens e adultos ${ }^{13}$. Segundo Monlevade e Ferreira (1998, p. 44), a razão da exclusão dessas categorias de ensino foi meramente financeira. Cada matrícula nova, principalmente em estados em que a União tem de completar o FUNDEF, significa menor custo/aluno médio e maior valor de aporte de verbas da União. Ainda para esses autores, essas categorias de ensino não poderiam ficar de fora por aglutinarem um número significativo de crianças, os quais os municípios teriam de assumir.

Ainda no que se refere à educação infantil, Melo (2003, p. 59) afirma ter havido, na década de 90 , acelerado processo de municipalização 
da pré-escola. A partir de 1993, essa oferta entra em declínio vertiginoso na rede estadual: das 242.684 matrículas, havia apenas $33.050 \mathrm{em} 2002$. Na rede municipal, por sua vez, o número de matrículas salta de 120.937 para 339.699, no mesmo período. Houve, na rede municipal, incremento significativo do número de matrículas, no período 1993-1998, e certa estabilização a partir de 1998. O pequeno aumento do número de matrículas na educação infantil, na rede estadual, ocorrida no período 2001/2002, se deve, segundo Melo (2003, p. 61), ao aproveitamento de servidores excedentes e das parcerias com prefeituras municipais.

A principal dificuldade ou inadequação relacionada ao FUNDEF apontada pelos secretários entrevistados vai ao encontro do que a literatura especializada tem considerado como uma das principais deficiências do Fundo: a limitação ao ensino fundamental e a exclusão da educação infantil, do ensino médio e de cursos de educação de jovens e adultos. A exclusão, principalmente, da educação infantil do rateio do FUNDEF tem sido o grande drama dos municípios mineiros, de acordo com a maioria dos entrevistados. Primeiramente porque o município se vê obrigado a arcar com todas as despesas a ela relacionadas. Em segundo porque ela favorece o surgimento de distorções salariais entre os professores do ensino fundamental e aqueles que trabalham na educação infantil e de jovens e adultos. Por haver essa diferenciação de remuneração, o secretário do município $\mathrm{K}$ afirma ter dificuldades em oferecer a sala de aula aos professores porque ninguém quer assumir a pré-escola.

Como forma de aliviar os municípios, a maioria dos secretários mencionou a necessidade de o FUNDEF se estender a toda a educação básica, sugerindo a alteração da sigla para FUNDEB (Fundo de Manutenção e Desenvolvimento da Educação Básica e de Valorização do Magistério). O secretário do município D considera essa exclusão injusta, uma vez que ela inviabiliza crianças de classes econômicas menos favorecidas de terem acesso a uma educação igualitária e de qualidade. Essa criança, desassistida por completo pelo sistema educacional até os sete anos de idade, entra para o ensino fundamental tendo de corresponder ou acompanhar o rendimento de crianças que tiveram oportunidades diferentes. $\mathrm{Na}$ fala do secretário:

O interessante é que o objeto desse programa são os alunos carentes. Estariam eles nascendo aos sete anos de idade? Grande parte do nosso atendimento é de alunos de subúrbio, alunos carentes, de famílias extremamente pobres e que não conseguem chegar à escola até os sete anos porque não têm como financiar uma escola particular, e o FUNDEF não 
contempla a educação infantil. Não há possibilidade de esse aluno adentrar no ensino se ele não tem apoio do Estado ${ }^{14}$.

A preocupação do secretário é pertinente. De acordo com Collucci e Góis (2003, p. c1), quase a totalidade dos brasileiros de maior renda tem acesso à pré-escola, o que significa que crianças de famílias de melhor poder aquisitivo já entram no ensino fundamental alfabetizadas ou tendo passado por uma sala de aula. Dados da Pesquisa Nacional por Amostra de Domicílios (PNAD) de 1999 mostram que a taxa de escolarização das crianças de quatro a seis anos de famílias com renda per capita maior que cinco salários mínimos é de $90 \%$. Entre as famílias com renda per capita inferior a meio salário mínimo, essa taxa é de apenas 50\% (IBGE, 2000).

Alguns municípios têm procurado alternativas para oferecer educação infantil. No município B, por exemplo, essa questão tem sido resolvida dividindo com o estado a responsabilidade pela oferta desse nível de ensino. Assim, tem-se, na zona rural, duas escolas estaduais como pólo de educação infantil e, na área urbana, duas escolas municipais (na periferia) que atendem a essa demanda. O município $\mathrm{C}$ tem oferecido educação infantil por meio de convênio junto à assistência social. A educação infantil tem sido oferecida por creches e pequenas escolas particulares. Já no município $G$, a secretária afirma que, com o recurso do FUNDEF, o município teve um pouco mais de folga em seu orçamento, o que possibilitou expandir o atendimento.

Segundo o secretário de educação do município $S$, a educação infantil só passou a ser responsabilidade do município a partir de 2002. No que respeita ao ensino médio, o secretário afirma que o atendimento a esse nível de ensino não acompanhou o crescimento que ocorreu no ensino fundamental. Com o afastamento do município na provisão do ensino médio e a incapacidade do estado em atender a alta demanda, e mesmo de não aceitar matrículas de alunos acima de 18 anos no ensino formal, o município não tem conseguido atender à demanda, que foi de 200 vagas no ano de 2001.

O impedimento aos alunos acima de 18 anos de cursarem o ensino médio tem sido também a preocupação da secretária do município C. Para ela, se o recurso do FUNDEF se estendesse para o ensino médio, a prefeitura poderia criar alternativas para esse público. 
Argumento 6: $\mathrm{O}$ valor/aluno não corresponde ao gasto com educação nos municípios.

O FUNDEF é composto por uma subvinculação das receitas de estados e municípios, complementada pela União. O valor das contribuições dos estados e municípios para o FUNDEF é um percentual fixo de receitas. Já a contribuição da União é flexível, devendo completar o necessário para que os recursos totais do Fundo contemplem a aplicação do valor de referência por aluno. O dispositivo legal que criou o FUNDEF, proposto pelo Governo Federal, é bom ressaltar, é claro quanto ao critério de cálculo desse valor de referência por aluno, no o art. $6^{\circ}$, parágrafo $1^{\circ}$ da Lei 9.424/96: "O valor mínimo anual por aluno, ressalvado o disposto no parágrafo $4^{\circ}$, será fixado por ato do Presidente da República e nunca será inferior à razão entre a previsão da receita total para o Fundo e a matrícula total do ensino fundamental no ano anterior, acrescida do total estimado de novas matrículas, observado o disposto no art. $2^{\circ}$, parágrafo $1^{\circ}$, incisos I e II'. Ora, quanto maior o valor de refe-rência, mais recursos a União tem de aportar ao FUNDEF, já que seu papel é complementar. Já estados e municípios têm contribuição fixa ao FUNDEF. Assim, é do interesse dos estados e municípios um valor de referência mais alto (já que isso não significa perdas adicionais e, para vários estados e municípios, pode representar maior aporte de recursos); do ponto de vista da União, o interesse é no menor valor possível, o que significa aporte menor de recursos. Como quem determina o valor de referência é a União, a tendência será de subestimação desse valor. $\mathrm{E}$ de fato foi o que ocorreu. Desde o primeiro ano de vigência, o valor mínimo de referência foi subestimado em relação ao estabelecido pela lei, como demonstra a Tabela 3. Além de seus efeitos gerais sobre o financiamento da educação fundamental no Brasil, para Minas Gerais essa subestimação teve efeitos ainda mais significativos (e negativos), pois implicou o não-recebimento de complementação ao estado, por parte da União. Ou seja, no caso de Minas Gerais, quaisquer ganhos adicionais foram resultantes de aumento de arrecadação ou de redistribuição interna entre os entes, já que não houve aporte adicional da União.

Segundo a maioria dos entrevistados, o Fundo não considera as especificidades de cada município. Para esses secretários, ele deveria diferenciar o valor dos alunos da zona rural e urbana, ou seja, as condições físicas, econômicas e sociais de todas as regiões beneficiadas deveriam ser consideradas.

Ainda segundo os entrevistados, o FUNDEF deveria abranger toda a educação básica e o valor do custo/aluno no ano deveria ser 
revisto, uma vez que ele tem sido deficitário desde a criação do Fundo. A insuficiência do recurso para sustentar as despesas que envolvem a educação, segundo os entrevistados, está relacionada à forma como ele tem sido calculado, uma vez que o cálculo considera o número de alunos matriculados no ano anterior. Entretanto, se existe aumento de alunos, existe de custos também, o que obriga o município a assumir um gasto por antecipação. A diferença de matrículas de um ano para outro é uma das críticas relacionadas ao FUNDEF apontadas por Monlevade e Ferreira (1998). O texto da lei diz que "a distribuição dos recursos, no âmbito de cada Estado e do Distrito Federal, dar-se-á entre o Governo Estadual e os Governos Municipais na proporção de alunos matriculados anualmente nas escolas cadastradas das respectivas redes de ensino". A lei não diz matriculada no ano anterior e, sim, anualmente. Isso levou a dificuldades na operacionalização do Fundo, dada a dificuldade de se ter estatísticas confiáveis nos estados e municípios, em janeiro do ano em curso. Como saída, criou-se o Decreto 2.264/97, que possibilitou basear o rateio do Fundo no censo do ano anterior.

Tabela 3: Diferença entre valor estabelecido em lei e valor determinado pelo decreto presidencial: impactos sobre o financiamento da educação em Minas Gerais (1998 - 2000)

\begin{tabular}{|c|c|c|c|c|c|c|c|c|}
\hline \multirow{7}{*}{ Ano } & \multirow[t]{7}{*}{ Nível } & (A) & (B) & (C) & (D) & (E) & (F) & (G) \\
\hline & & Valor & Valor & Valor & (B e & Matrícula & Matrícula & $(\mathrm{D} \times \mathrm{E})^{* 1+2 k}$ \\
\hline & & mínimo & mínimo & mínimo & C)Difere & /Ano em & Total em & Déficit MG \\
\hline & & anual & anual por & anual por & nça não- & Minas & Minas & Em \\
\hline & & por & aluno em & aluno de & recebida & Gerais & Gerais & $\mathrm{R} \$ 1.000,00$ \\
\hline & & aluno* & Minas & do & por & & & \\
\hline & & & & con & Mlit & & & \\
\hline \multirow[t]{2}{*}{1998} & & $\mathrm{R} \$ 315,00$ & $\mathrm{R} \$ 354,22$ & $\mathrm{R} \$ 418,77$ & $\mathrm{R} \$ 64,55$ & 3.468 .839 & 3.468 .839 & $\mathrm{R} \$ 223.913,00$ \\
\hline & Fund & & & & & & & \\
\hline \multirow[t]{2}{*}{1999} & En & $\$ 315,00$ & $\mathrm{R} \$ 389,75$ & $\mathrm{R} \$ 449,96$ & $\mathrm{R} \$ 60,21$ & 3.657 .558 & 3.657 .558 & $\mathrm{R} \$ 220.221,00$ \\
\hline & Fund & & & & & & & \\
\hline \multirow[t]{3}{*}{2000} & $1^{\mathrm{a}}$ a $4^{\mathrm{a}}$ & $\mathrm{R} \$ 333,00$ & $\mathrm{R} \$ 451,71$ & $\mathrm{R} \$ 511,30$ & $\mathrm{R} \$ 59,59$ & 1.835 .501 & & $\mathrm{R} \$ 109.377,50$ \\
\hline & $5^{\mathrm{a}}$ a $8^{\mathrm{a}}$ & $\mathrm{R} \$ 349,65$ & $\mathrm{R} \$ 474,30$ & $\mathrm{R} \$ 536,90$ & $\mathrm{R} \$ 62,60$ & 1.732 .858 & 3.577 .550 & $\mathrm{R} \$ 108.476,91$ \\
\hline & Ed. Especial & $\mathrm{R} \$ 349,65$ & $\mathrm{R} \$ 474,30$ & $\mathrm{R} \$ 536,90$ & $\mathrm{R} \$ 62,60$ & 9.191 & & $\mathrm{R} \$ 575,36$ \\
\hline
\end{tabular}

Fonte e elaboração: SEE/MG

* Valor mínimo anual por aluno fixado, respectivamente, pelos Decretos: n. 2.440/97; n. 2.935/99 e n. 3.326/99.

** Estado de Minas Gerais apresenta valor mínimo anual por aluno superior ao fixado nacionalmente, daí a diferença ente (A) e (B) com relação aos valores.

*** Art. $6^{\circ}, \mathbb{} 1^{\circ}$, da Lei n. 9.424/96 determina fórmula a ser seguida para 
fixação do valor mínimo anual por aluno. O governo federal não tem observado o disposto no art. $6^{\circ}, \int 1^{\circ}$, da Lei n. 9.424/96 para efetuar o cálculo do valor mínimo por aluno, daí a diferença entre $(\mathrm{A})$ e $(\mathrm{C})$ com relação aos valores.

**** (D) indica a diferença entre (B) e (C), mostrando que o estado de Minas Gerais, mesmo apresentando valor acima daquele fixado nacionalmente, estaria com valor defasado e deveria receber complementação de recursos da União, se fosse obedecido o disposto no art. $6^{\circ}, \S 1^{\circ}$, da Lei n. 9.424/96, para fixação do valor mínimo anual por aluno.

***** Observando-se a diferença não-recebida por Minas Gerais (D) e o número de matrículas por ano no Estado (E), é possível obter o valor do déficit do estado em relação aos recursos do FUNDEF, se fosse respeitado o disposto no art. $6^{\circ}$, $\int 1^{\circ}$, da Lei n. 9.424/96, para fixação do valor mínimo anual por aluno.

A partir de 2000, o governo implementou a diferenciação dos valores per capita de $1^{\mathrm{a}}$ a $4^{\mathrm{a}}$ e de $5^{\mathrm{a}}$ a $8^{\mathrm{a}}$ séries.

O secretário de educação do município A afirma que tem dificuldade em aumentar os salários dos professores dentro dos $60 \%$ de recursos previstos pelo FUNDEF, tanto porque o recurso é calculado com base na matrícula do ano anterior, quanto pelo aumento do número de funcionários (mais professores para atender a demanda atual) e valor per capita por aluno recebido. Segundo o secretário, em razão dessas inadequações, o valor repassado tem sido insuficiente para promover o crescimento real do valor de salário pago ao professor.

Já o município F tem acumulado, a cada ano, perdas significativas do ponto de vista financeiro que são atribuídas a dois fatores principais: o fato de possuir arrecadação satisfatória (acima da média dos demais municípios do mesmo porte) em decorrência das mineradoras lá existentes, o que faz com que o valor destinado ao fundo seja muito maior do que aquele que retorna segundo os critérios de partição do FUNDEF, e a queda crônica do número de alunos matriculados nas redes municipal e estadual a cada ano. Segundo a secretária, essa situação tem promovido uma disputa entre as redes de ensino no sentido de obter o número suficiente de alunos para se manterem funcionando.

Também, para grande parte dos secretários (municípios L, R, P, M, G, H, D e A), a maior dificuldade tem sido a insuficiência do recurso em relação às despesas do município. Os recursos do FUNDEF não permitem grandes investimentos na rede de ensino, pois a maioria é despendida na folha de pessoal. Essa situação se deve ao fato de a União não fazer as correções necessárias ao valor per capita, o que faz com os municípios tenham de arcar com recursos adicionais. A perpetuação dessa situação tende a aumentar cada vez mais a proporção de recursos gastos 
com folha de pagamento, o que faz com as escolas sofram grande depreciação por não poderem ser reformadas, diminuindo o capital físico do município.

Houve críticas também ao formato rígido do gasto do recurso que condiciona, no mínimo, $60 \%$ para investimento em profissionais do magistério $^{15}$ e $40 \%$ nas demais despesas. Para os secretários, tal procedimento tem prejudicado o desenvolvimento das atividades educacionais. O gasto com transporte escolar, por exemplo, que atende a rede educacional rural, tem sido dispendioso em função das péssimas condições das vias. "As condições locais tornam os gastos muito grandes frente ao fundo repassado"11.

\section{CONSIDERACְÕES FINAIS}

O FUNDEF é um arranjo institucional de incentivo para que a manutenção e o desenvolvimento do ensino fundamental fossem o foco das políticas no setor, baseado no envolvimento das três esferas federadas, mas crescentemente sob a responsabilidade dos municípios. Trata-se de uma decisão planejada do poder público federal, apesar de o conceito vir de antes e estar já contido no Plano Decenal de Educação, intencionalmente dirigida e talvez a única política a apresentar resultados parcialmente positivos. Municípios que jamais haviam investido em educação fundamental, sob pena de perdas de recursos, se viram compelidos a repensar suas políticas para o setor.

Pode-se perceber que os impactos relacionados ao FUNDEF são de três tipos: administrativo-financeiro, de infra-estrutura escolar e de valorização docente. $\mathrm{O}$ primeiro envolve a existência de uma rubrica própria para a educação, maior autonomia dos gestores e transparência na utilização dos recursos; o segundo refere-se a reforma e construção de prédios, compra de material didático e transporte; o terceiro refere-se à melhoria na remuneração do professor, regularidade do pagamento e programas de capacitação.

Tais aspectos vão ao encontro da reorganização pretendida pelo Fundo que seria: criar incentivos para que municípios com melhores condições fiscais e atendimento relativamente baixo ampliassem sua rede; e proporcionar melhores condições aos municípios com situação fiscal relativamente mais difícil e que já realizavam um esforço significativo de atendimento, para que pudessem oferecer serviços de melhor qualidade e remunerar mais adequadamente os professores.

Observa-se que a dificuldade de financiamento tem sido um limitador para os municípios, que têm buscado alternativas menos 
onerosas para cumprir com essa responsabilidade, como, por exemplo, a criação de convênios e o estabelecimento de parcerias com o estado.

Merece destaque, também, a necessidade de se repensar os valores repassados pelo Fundo, que, em muitos municípios, não tem correspondido ao custo/aluno real. Essa inexatidão faz com o recurso repassado seja insuficiente para cobrir todos os gastos que o município tem com a educação e, em muitos casos, seja suficiente apenas para o pagamento do salário do professorado.

Ainda que esse seja o objetivo principal do Fundo e que professores bem-remunerados sejam uma condição importante para a melhoria da qualidade do ensino, essa, por si só, é condição insuficiente, uma vez que melhor salário não garante bons professores. O que pode dar alguma garantia é a associação de um conjunto de fatores: professores bem-pagos, formados, com acesso a formação continuada, escolas bemequipadas, boas condições de trabalho e outros. Nesse sentido, é questionável um recurso que vise a melhorar a qualidade da educação e seja suficiente apenas para o pagamento da folha de professores.

Por fim, as entrevistas com os Secretários Municipais de Educação permitem afirmar que a implantação do FUNDEF foi positiva, no sentido de promover benefícios na área educacional. Em alguns municípios ( $\mathrm{T}, \mathrm{P}, \mathrm{K}, \mathrm{J})$, tornou-se possível a promoção da discussão do controle público, a pontualidade do repasse do Fundo, a melhoria do transporte escolar e a eqüidade na distribuição dos recursos financeiros no estado. Os municípios passam a contar com maior autonomia para gerir os recursos destinados ao ensino fundamental. Apesar das críticas citadas, o FUNDEF é visto pelos entrevistados como um dos mais bemintencionados planos e tem viabilizado o desenvolvimento e a manutenção do ensino público no Brasil diante dos já percebidos problemas enfrentados pela administração pública.

Destaca-se que os impactos e/ou dificuldades apontados pelos entrevistados ocorreram independentemente de o município ser ganhador ou perdedor com o rateio do FUNDEF. Sendo assim, os problemas parecem estar mais relacionados ao sistema educacional e às "falhas" na legislação. Só a vinculação de uma rubrica que garante $60 \%$ para pagamento de professores já tem possibilitado certa segurança para melhorar a educação no município. Desse ponto de vista, a garantia de alocação de insumos (recursos financeiros, quantidade e qualidade do corpo docente, equipamentos e outros) já seria uma contribuição importante para a política educacional dos municípios mineiros. 
De maneira geral, os problemas identificados são consistentes com o que vem sendo tratado na literatura. O FUNDEF parece ter sido capaz de alterar substantivamente as condições e a distribuição da oferta educacional em Minas Gerais. De forma geral, seus efeitos positivos parecem superar largamente as lacunas e os problemas detectados. Entretanto, foram identificados vários efeitos não-desejados, lacunas ou insuficiências do Fundo, no tocante: a) às relações intergovernamentais; b) aos mecanismos de pactuação e de transição no processo de municipalização; c) ao apoio técnico e institucional necessários para a reorganização bem-sucedida da oferta entre os entes; d) aos problemas de eqüidade na oferta de ensino, que permanecem, em alguns casos, e se agravam, em outros; e) às conseqüências da focalização exclusiva no ensino fundamental, e não na educação básica; f) à qualidade e à eqüidade da formação docente.

Alguns dos problemas discutidos aqui já haviam sido antecipados na tramitação da proposta, como a participação da União na composição do Fundo e a exclusão de outros níveis de ensino. Tanto assim que o FUNDEB, em vigência a partir de 2007, procura corrigir alguns desses pontos, ao incluir no Fundo os níveis médio e infantil, ao garantir uma contribuição maior da União em sua composição e ao apontar para pisos mínimos de remuneração docente. Entretanto, nem todos os problemas de coordenação podem ser resolvidos por mecanismos alocativos e automáticos como o FUNDEF (ou o FUNDEB). É preciso que os estados assumam o papel de coordenação, inclusive assessorando as redes municipais, regulando e qualificando os processos de municipalização, estabelecendo critérios e metas de qualidade e eqüidade nos diferentes níveis de ensino. Por outro lado, a formação docente permanece um problema. O Fundo tem servido para custear principalmente iniciativas mais específicas e de ciclo mais curto de capacitação. Não obstante sua relevância, essas iniciativas não substituem o investimento na formação inicial dos docentes. Se há acordo sobre a necessidade de se aumentar a escolaridade docente, iniciativas específicas para este fim têm de ser desenvolvidas, pois, ao que tudo indica, o mecanismo indireto de indução, representado pelo FUNDEF, não tem sido suficiente para alterar significativamente a formação dos professores. 


\section{REFERÊNCIAS}

BRASIL. Ministério da Educação e Cultura. Lei n. 9.394/1996. Estabelece as diretrizes e bases da educação nacional.

BRASIL. Ministério da Educação e Cultura. Lei n. 9424 de 24 de dezembro de 1996. Dispõe sobre o Fundo de manutenção e Desenvolvimento do Ensino Fundamental e de Valorização do Magistério.

MINISTÉRIO DA EDUCAÇÃO. Balanço do $1^{\circ}$ ano do FUNDEF. Brasília, mar., 1999.

BRASIL. Ministério da Educação. Balanço do $1^{\circ}$ ano do FUNDEF. Brasília. mar., 1999. Síntese para a Imprensa.

COLLUCCI, C.; GÓIS, A. Falta de tratamento diferenciado pode prejudicar. Folha de S.Paulo, São Paulo, 8 de junho de 2003. Caderno Cotidiano, p. c1.

CONFEDERAÇÃO NACIONAL DOS TRABALHADORES EM EDUCAÇÃO. Avaliação do primeiro ano do FUNDEF. Brasília, 1999. Documento avulso.

COSTA, B. L. D.; VEIGA, L. Eqüidade no ensino fundamental em Minas Gerais: uma avaliação exploratória. Mosaico, v. n. 2002.

FEDERAÇÃO DAS ASSOCIAÇÕES E CÍRCULOS DE PAIS E MESTRES DO RIO

GRANDE DO SUL. Análise do $1^{\circ}$ ano de criação do FUNDEF sob a ótica do segmento de pais. Rio Grande do Sul, 1999.

FERREIRA, A. L. Educação infantil: direito da criança, dever do estado e opção da família. Dissertação (Mestrado em Administração Pública). Escola de Governo/Fundação João Pinheiro, Belo Horizonte, 2002.

ÍNDICE DE CONDIÇÕES de vida nos municípios de Minas Gerais 1970, 1980 e 1991. Belo Horizonte: Fundação João Pinheiro/Instituto de Pesquisa Econômica Aplicada. 1996, 244p.

MEC/INEP. Censo Escolar 2001.

INSTITUTO BRASILEIRO DE GEOGRAFIA E ESTATÍSTICA (IBGE). Síntese de indicadores sociais 2000.

http://www.ibge.gov.br/home/estatistica/populacao/condicaodevida/indicadoresmini mos/sintesedeindicsociais2000.shtm.

MELO, F. N. de. A qualidade na educação infantil. Monografia (Curso de Especialização em Políticas Públicas e Gestão Governamental). Escola de Governo/Fundação João Pinheiro, Belo Horizonte, 2003.

MELO, T. C. A. de. O financiamento da educação básica brasileira: implicações para a política educacional em municípios mineiros. Dissertação (Mestrado em Administração Pública). Escola de Governo/Fundação João Pinheiro, Belo Horizonte, 2000.

MONLEVADE, J.; FERREIRA, E. B. O FUNDEF e seus pecados capitais. 2.ed. Brasília: Idéia, 1998.

PLANK, David N. Política educacional no Brasil: caminhos para a salvação pública. São Paulo: Artmed, 2001.

SANTOS, M. C. R. dos. A vinculação de recursos em Minas Gerais a partir de 1988 e sua relação com o atendimento à universalização do ensino e à remuneração dos profissionais do magistério. Monografia (Curso de Especialização em Orçamento e Finanças Públicos). Escola de Governo/Fundação João Pinheiro, Belo Horizonte, 2003.

XAVIER, Antônio C. da R.; MARQUES, A. E. S. O custo aluno no ensino fundamental brasileiro. Brasília, IPEA, 1991 (Mimeogr.). 


\section{NOTAS}

${ }^{1}$ A base empírica do trabalho é a pesquisa O FUNDEF e a municipalização em Minas Gerais: relações intergovernamentais, equidade e controle público, financiada pela Fundação Ford, $2002 / 2004$.

${ }^{2}$ Quando o próprio secretário não estava disponível, outro representante legal foi entrevistado. Em um caso, a prefeita e, em outro, um servidor.

${ }^{3} \mathrm{Na}$ análise dos dados obtidos por meio da pesquisa, serão utilizados nomes fictícios visando a resguardar a identidade dos municípios.

Fundo de Participação dos Estados (FPE), Fundo de Participação dos Municípios (FPM), Imposto sobre Circulação de Mercadorias e Serviços (ICMS), Cota municipal do ICMS, Imposto sobre Produtos Industrializados proporcional exportações (IPI-EXP), Cota municipal do IPI-EXP, Lei Complementar n. 87/96 (Lei Kandir), Lei Complementar n. 87/96 (Lei Kandir destinada aos municípios).

${ }^{4}$ Entende-se por manutenção e desenvolvimento do ensino o estabelecido no art. 70 da Lei 9394/96 - LDB: remuneração e aperfeiçoamento de pessoal docente e demais profissionais da educação; aquisição, manutenção, construção e conservação de instalações e equipamentos necessários ao ensino; uso e manutenção de bens e serviços vinculados ao ensino; levantamentos estatísticos, estudos e pesquisas visando ao aprimoramento da qualidade e a expansão do ensino; realização de atividades-meio necessárias ao funcionamento dos sistemas de ensino; concessão de bolsas de estudos.

${ }^{5}$ Entrevista realizada em dez. 2002 (Funcionária da SME).

${ }^{6}$ Tal informação foi retirada tanto de entrevistas com secretários quanto das visitas às escolas em dez. 2002.

${ }^{7}$ Entrevista realizada em dez. 2002 - Prefeita

${ }^{8}$ O Projeto Veredas é um curso de normal superior oferecido pela Secretaria Estadual de Educação visando a dar formação de nível superior aos professores da rede pública.

${ }^{9}$ Programa de Capacitação de Professores (PROCAP) e Programa de Capacitação de Diretores (PROCAD) realizado pela Secretaria de Estado da Educação no período 1998/2000.

${ }^{10}$ Embora o Projeto Veredas seja estadual, os municípios puderam participar, financiando a participação de seus professores (aprovados no concurso) junto às agências capacitadoras. Muitos foram financiados com recursos do FUNDEF.

${ }^{11}$ Os conselhos de acompanhamento não são objeto específico deste artigo. Entretanto, em outro trabalho - "Desafios para o Controle Público: os Conselhos de Acompanhamento do FUNDEF", apresentado no ENANPAD 2005 - é exposto o resultado de pesquisa com membros dos CACS destes mesmos municípios. Os resultados apontam que, apesar de terem contribuído significativamente para o aperfeiçoamento e para o controle público sobre o uso dos recursos do Fundo, os conselhos de acompanhamento ainda enfrentam problemas oriundos de limitações do próprio desenho institucional; da assimetria de capacidades entre atores governamentais e não-governamentais; dos custos desiguais da participação; além de problemas propriamente políticos.

${ }^{12}$ Entrevista realizada em dez. 2002.

${ }^{13}$ Educação para jovens e adultos que não tiveram acesso ao ensino fundamental em 
idade própria e garantia da continuidade da escolarização para os que freqüentam o ensino fundamental.

${ }^{14}$ Entrevista realizada em dez. 2002.

${ }^{15}$ Há ambigüidade na legislação quanto a este item: enquanto a EC 14 refere-se a professores, a legislação que regulamenta o Fundo utiliza o termo mais genérico "profissionais do magistério".

${ }^{16}$ Há ambigüidade na legislação quanto a este item: enquanto a EC 14 refere-se a professores, a legislação que regulamenta o Fundo utiliza o termo mais genérico "profissionais do magistério".

${ }^{17}$ Entrevista realizada em dez. 2002 - Secretário.

Recebido: 18/07/2006

Aprovado: 25/03/2008

Contato:

Fundação João Pinheiro

Alameda das Acácias, 70

Pampulha

Belo Horizonte - MG

Brasil

E-mail: bruno.diniz@fjp.mg.gov.br 